\title{
LAS PERÍFRASIS VERBALES DE GERUNDIO EN EL HABLA URBANA CULTA DE SEVILLA: CARACTERIZACIÓN Y USO DISCURSIVO ${ }^{1}$
}

\author{
Juana Santana Marrero
}

\begin{abstract}
This work involves two main aims: first, to carry out a syntactic-semantic characterization of the verbal periphrasis with the gerund and, second, to analyse the discoursive uses of such sequences in Sevillian educated speech. We have supported that verbal periphrasis must be defined with syntactic criteria. Apart from that, there is a syntactic and semantic interdependence relation between the conjugated verbal form and the gerund. Verbal periprasis are discoursive items, caused by an enunciation process, and they acquire a periphrastic pragmatic behaviour in communicative contexts. After having analysed the corpora of Sevillian educated speech, it was observed that estar + gerund was the most frequently periphrastic sequence, used to express the verbal action in process. There was also an important amount of occurrences of ir + gerund which mainly expresed a progressive verbal action. The rest of the periphrastic constructions found in the corpora (seguir, continuar, andar and salir + gerund) were less frequent. Verbal periphrasis are discoursive resources that contribute to solve the speakers' communicative necessities and to add expressive richness to language.
\end{abstract}

\section{PRESENTACIÓN}

El sistema verbal español cuenta con un amplio número de unidades que conforman un paradigma rico en recursos para la expresión de matices de tiempo, modo y aspecto. A esta riqueza es preciso sumar las llamadas perífrasis verbales que contribuyen a satisfacer las necesidades comunicativas de los hablantes, superando las posibilidades del paradigma verbal.

El objetivo de este trabajo es la caracterización y análisis de las perírrasis verbales de gerundio empleadas por los hablantes sevillanos cultos. Para ello utilizamos un corpus de textos orales compuesto por las encuestas del habla urbana culta de Sevilla (Cf. V. Lamíquiz y M. A. Pineda, 1983). El material está formado por 24 entrevistas de una duración aproximada de media hora cada una en las que la conversación se centra en temas de interés general tales como la vida diaria, la Feria, la Semana Santa, entre otros, con el fin de que el informante se exprese de forma espontánea y relajada. Las grabaciones fueron realizadas a personas que hubieran nacido en Sevilla o que hubieran desarrollado la mayor parte de sus años en dicha capital y que estuvieran plenamente integrados en la vida de la

\footnotetext{
${ }^{1}$ Una versión resumida de este trabajo fue leída como comunicación en el XIII Encuentro de la Asociación de Jóvenes Lingüistas celebrado en Salamanca el 22 de mayo de 1998, publicada en Interlingüística, 9, 301-304.
} 
ciudad (Cf. V. Lamíquiz y P. Carbonero, 1981). Fueron considerados hablantes cultos aquéllos que fueran licenciados universitarios o con estudios superiores. Todos ellos fueron clasificados en tres grupos de edad ( $1^{\mathbf{a}}$ generación hasta los 30 años, $2^{\mathrm{a}}$ generación de los 31 a los 45 años y $3^{\mathrm{a}}$ generación de los 46 años en adelante) y atendiendo a la variable sexo, hombre y mujer. Esto constituye un total de seis casillas sociolingüísticas diferentes que, multiplicado por cuatro informantes de las mismas características, hace un total de 24 encuestas analizadas.

\section{CARACTERIZACIÓN}

Existe una extensa bibliografía (artículos y monografías) dedicada al estudio de las perífrasis verbales. Además, las gramáticas reservan un espacio destinado a su análisis y clasificación. No obstante, llama la atención la falta de homogeneidad entre los autores que se han ocupado de su estudio. Esto se debe a que en el análisis de estas unidades lingüísticas se agrupan diversos problemas que complican su caracterización. No sólo se plantea la necesidad de establecer las características que definen al llamado verbo auxiliar, sino que no existe un consenso unánime en lo que se refiere a la denominación de las perífrasis, a los criterios que sirven para su delimitación ni al número de unidades que las conforman.

Entendemos por perífrasis verbal ia unión de dos formas verbales, una flexiva y otra no flexiva $^{2}$, que se agrupan para constituir una secuencia unifuncional (núcleo del predicado) y una sola unidad de sentido. La dificultad estriba en averiguar hasta qué punto se ha producido la fusión en una forma predicativa única, o, como se ha dicho en otras ocasiones, cuándo el verbo flexionado se convierte en un auxiliar. No siempre que aparecen unidas en el sintagma una forma flexiva y otra no flexiva de infinitivo, gerundio o participio constituyen una perífrasis verbal. De este modo, consideramos de gran utilidad la distinción que hace G. Rojo (1974:60 y ss.) entre complejos verbales no perifrásticos y complejos verbales perifrásticos.

En este artículo nos detendremos, en un primer momento, en la delimitación de las particularidades de los complejos verbales perifrásticos. En un segundo momento nos centraremos en la descripción y clasificación de las perífrasis verbales de gerundio utilizadas por los hablantes sevillanos cultos ${ }^{3}$.

\footnotetext{
${ }^{2}$ El infinitivo, gerundio y participio han recibido diversas denominaciones. La más extendida es quizás la de formas no personales del verbo (Cf. RAE, 1973; M. Launay, 1980; L. Gómez Torrego, 1988), aunque también pueden registrarse otras como la de formas nominales (Cf. J. Roca Pons, 1958; ) y la de verboide, propuesta por R. Lenz (1925) (Cf. E. Luna, 1980. M. Arjona, 1992). Siguiendo a C. Bobes (1975:1) optamos por la denominación de formas no flexivas del verbo (frente a las flexivas o flexionadas) pues creemos que se ajusta con mayor fidelidad a lo que caracteriza al infinitivo, gerundio y al participio, que es la ausencia de cualquier desinencia del verbo y no solamente aquélla que se refiere a la persona.

${ }^{3}$ Para un estudio en el que se analiza el uso del gerundioen el mismo corpus Cf. F. Rodríguez-Izquierdo, 1981,
} 


\subsection{Criterios para la delimitación}

Resulta difícil, si no imposible, separar el estudio de las perífrasis verbales del llamado verbo auxiliar. M. Launay (1980:40) advirtió que entre ambas cuestiones, perífrasis y auxiliaridad, existe una especie de "circularidad viciosa" pues para definir una se acude necesariamente a la otra. Se entiende que un complejo verbal se convierte en perifrástico cuando una de las dos formas verbales pierde las facultades que le permiten funcionar como unidad predicativa plena $y$, en este sentido, necesita de otra forma verbal en la que apoyarse. De la unión de ambas resulta la perífrasis verbal.

Si bien no existe una opinión conjunta acerca de los límites de la noción de auxiliaridad, no está en nuestro ánimo emprender la tarea de acotar los rasgos que definen la auxiliaridad del verbo, labor que superaría con mucho los objetivos de este trabajo. Sí creemos necesario mantener una actitud crítica ante los postulados manejados hasta el momento y exponer el planteamiento que seguiremos.

Uno de los principales criterios utilizados para la delimitación de la noción de verbo auxiliar ha sido la desemantización de la unidad verbal o, lo que es lo mismo, su gramaticalización. Esto supone la transformación en apoyatura formal de un verbo conceptual, que pierde su carga semántica, y además aporta a otro verbo los morfemas de tiempo, modo, persona y número. El Esbozo de la RAE (1973:444) expone de forma precisa: "Decimos que un verbo desempeña la función de auxiliar cuando, al encabezar una perífrasis verbal, pierde total o parcialmente su significado propio." Se admite, por lo tanto, un proceso de gradación por el cual, en la formación del auxiliar hay casos que oscilan entre el oscurecimiento y la pérdida total del significado. S. Gili Gaya (1943:105) lleva hasta sus últimas consecuencias el criterio de pérdida de significación como argumento para la formación de un auxiliar cuando dice que "Para distinguir si un verbo está empleado como auxiliar basta fijarse si ha perdido su significado propio." Tal rigurosidad en su planteamiento le lleva a manifestar serias dudas acerca del carácter de construcción perifrástica de algunos complejos verbales como estar + gerundio en casos como está durmiendo tranquilo en los que el verbo en forma flexiva conserva su significación plena.

No faltan quienes consideran que el factor de la desemantización o gramaticalización no es suficiente para la formación de un verbo auxiliar y, consecuentemente, para la creación de una perífrasis verbal. De este modo, L. Gómez Torrego (1988:14-15) apunta que, aunque es importante el proceso de gramaticalización que se produce en los verbos auxiliares, también es necesario tener en cuenta unos criterios formales identifiquen a la perífrasis verbal. M. Launay (1980:41 y ss.) expone la inadecuación de la pérdida de sentido pleno de un verbo como factor determinante en su gramaticalización. No sólo aparecen numerosas excepciones (verbos que, a pesar de conservar su significado, funcionan como auxiliares) sino que también, argumenta el autor, el panorama se complica con la noción de semiauxiliar o de semiperífrasis por la cual se entiende que la forma verbal conjugada aún conserva cierto grado de su valor semántico originario (Cf. J. Roca Pons, 1958; L. Gómez Torrego, 1988; R. Fente et al., 1972). 
A partir de ahora consideraremos que no es posible sostener la desemantización de un verbo como único argumento en el que se cimiente la formación de un verbo auxiliar y, consecuentemente, la creación de una perífrasis verbal. El significado se entiende como un continuo donde no resulta fácil establecer los límites entre el valor semántico pleno y las posteriores pérdidas parciales del contenido de la unidad léxica. En el debilitamiento semántico se aprecian zonas de indeterminación que no permiten marcar unos límites fijos con facilidad. Necesitamos, por lo tanto, otros criterios que, junto con el semántico, expliquen el proceso de formación de la perífrasis verbal.

Fue en el ámbito de la gramática transformacional donde surgieron nuevas propuestas para la delimitación de la auxiliaridad y, paralelamente, para la identificación de la perífrasis verbal. El trabajo de $\mathrm{M}^{\mathrm{a}} \mathrm{B}$. Fontanella (1970) fue pionero en establecer criterios formales para acotar las fronteras de los verbos auxiliares españoles. Se desecharon los rasgos de semánticos de pérdida de significación que, como vimos, resultaban problemáticos, para considerar ciertas reglas sintácticas que se cumplieran en los complejos verbales perifrásticos. Ma . B. Fontanella (1970:61) estableció como parámetros básicos la "relación gramatical con otros constituyentes de la oración, posibilidad de construcción con elementos equivalentes a los verboides, comportamiento frente a la transformación pasiva, comportamiento en la transformación interrogativa y posibilidad de construcciones ambiguas."

Los criterios empleados por la citada autora han sido adoptados y reformulados en posteriores trabajos. En C. Hernández (1984:482 y ss.) encontramos una exposición detallada de los principales indicios sintáctico-funcionales que permiten delimitar la existencia de un complejo verbal perifrástico. Haciendo una síntesis apretada de las principales aportaciones de trabajos anteriores al nuestro, a continuación exponemos los rasgos que entendemos permiten una delimitación bastante rigurosa de la noción de perífrasis verbal. La variedad de matices de las perífrasis verbales unido a su complicada definición justifica que existan casos en los que no se cumplan de forma unánime todos los rasgos sintácticos que señalamos.

1. Las perífrasis verbales representan la agrupación de dos formas verbales independientes en una sola unidad funcional y de sentido. La conversión en un solo núcleo predicativo exige la existencia de un único sujeto y permite la conmutación paradigmática por una forma verbal simple.

"También tenía una monja que estudiaba... Mientras nos daba clase a los alumnos, estaba estudiando la carrera de Filosofía y Letras." C1H2068

\section{La monja estudiaba}

2. Un complejo verbal perifrástico implica la superación de la autonomía de sus dos unidades constituyentes para formar un solo núcleo predicativo. De este modo, no es posible reflejar en una estructura disjunta las dos formas verbales como dos acciones independientes. Esto es, el complejo verbal perifrástico es un grupo funcional que no admite su separación en una secuencia disjunta (Cf. B. Pottier, 1968:198). 
"Elegí Arte que es la especialidad, como dije antes, que ahora estoy haciendo." C1H2069

* ahora estoy y hago

*ahora estoy mientras hago

3. La forma verbal no flexiva es una parte del núcleo predicativo y no un modificador del verbo conjugado que cumple una función en la oración. De este modo, no es posible la conmutación de la primera por sustitutos pronominales o secuencias sintagmáticas que indiquen un funcionamiento adverbial ${ }^{4}$.

"Comparece el secretario, que es el que va tomando nota de todo." C2V4146

*Va así

*Va de este modo

4. Los complejos verbales perifrásticos reflejan un comportamiento con respecto a la interrogación que los diferencia de los no perifrásticos. En los primeros, la forma no flexiva del verbo no constituye una unidad funcional externa al núcleo verbal. De esta forma, no permite la interrogación parcial donde el pronombre focaliza uno de los huecos funcionales de la oración.

“[...] pero en realidad, es lo que contribuye para que el pueblo siga pensando en la Semana Santa y en que, en fin, este deseo de querer a la Virgen y en general ser amante aquí en Sevilla." C1V2023

* ¿Cómo sigue? pensando en la Semana Santa...

* ¿Qué sigue? pensando en la Semana Santa...

¿Qué sigue haciendo? sigue pensando en la Semana Santa...

5. La forma verbal flexiva de una perífrasis ha perdido su régimen propio (los modificadores que acompañan al verbo) y adopta los de la forma verbal no flexionada.

"Creo que es necesario, primero, en realidad por dinero, para qué vamos a decir lo contrario, pero también porque creo que la enseñanza nos mantiene siempre en contacto con la juventud, con los problemas que ella sucesivamente va teniendo." C1H2074

Tener puede llevar implemento (problemas) pero no el verbo ir

\subsection{Relaciones de dependencia: sintaxis y semántica}

Como se ha visto hasta el momento, las construcciones perifrásticas están constituidas por dos unidades verbales que se agrupan para formar un solo núcleo funcional predicativo. Ahora bien, ¿cuál es la relación que existe entre las dos partes constituyentes?.

\footnotetext{
${ }^{4}$ Se entiende el término adverbial en su sentido etimológico de lo que complementa al verbo, considerando este último como el núcleo del sintagma verbal o como su expansión en la unidad oracional. (Cf. P. Carbonero, 1993).
} 
Como bien es sabido L. Hjelmslev (1943) propuso la distinción de tres tipos de relaciones de dependencia que pueden ser aplicadas a todas las unidades lingüísticas: constelación (coordinación), determinación (subordinación) e interdependencia. Rechazamos de entrada la relación de constelación o coordinación entre las dos unidades verbales que forman la perífrasis pues, como dijimos, constituye una forma de destruir su unidad sintáctica. Otras dos posibles interpretaciones son la relación de subordinación y la de interdependencia.

Es frecuente encontrar en los tratados una explicación de la que es posible deducir una relación de subordinación entre las dos partes que forman una perífrasis verbal. En ellos se dice que la forma flexiva del verbo es, como se ha visto, la unidad auxiliar que ha perdido su significado propio para convertirse en una apoyatura formal de las desinencias de tiempo, modo, persona y número. Dicho verbo conjugado ya no tiene autonomía funcional. Por otro lado, la forma verbal no conjugada aporta al conjunto la base conceptual y es, en este sentido, el verbo auxiliado. La terminología empleada, en principio, nos lleva a pensar que el auxiliar ejerce un servicio sobre el auxiliado, el cual es el receptor pasivo de la acción gramatical del primero. De este modo se deduce que el primero se subordina o somete a las exigencias semánticas y sintácticas del segundo. Así, para F. Marcos Marín (1972:188) la gramaticalización del verbo auxiliar lo convierte en un "útil gramatical". R. Seco (1931:171-172) señala que en las frases verbales "es el verbo auxiliar (como sucede en los tiempos compuestos) el que señala todos los necesarios accidentes verbales". Para J. Roca Pons (1960: 235) la característica que une a los verbos auxiliares y a los copulativos es que ambos "han perdido su verdadera significación y se han convertido en puros instrumentos gramaticales." Dicha relación de subordinación, aunque no se enuncie de forma explícita, puede deducirse de la explicación de L. Gómez Torrego (1988:9) en tanto que hace uso del término principal, lo que presupone otro no principal o secundario o subordinado: "Entendemos por perífrasis verbal la unión de dos o más verbos que sintácticamente constituyen un solo núcleo del predicado. De este conjunto verbal, el verbo principal o auxiliado debe ser una forma no personal: infinitivo, gerundio o participio; el otro (o otros) verbo es siempre un mero auxiliar, pero será la forma que podrá conjugarse en todas o algunas de las formas de la conjugación."

Con lo dicho hasta el momento, planteamos que la subordinación no refleja con fidelidad la relación entre las dos formas verbales de las construcciones perifrásticas. Creemos que entre aquéllas existe una relación de interdependencia o exigencia mutua (Cf. F. Fernández de Castro, 1990) que les permite constituirse en un todo sintáctico y semántico diferente a las unidades integrantes. Ambas formas constituyen una parte imprescindible del todo, del núcleo del predicado. Una relación de subordinación pondría de manifiesto la existencia de un complejo verbal no perifrástico, un grupo disjunto, en el que la forma verbal no flexiva funcionaría como un modificador no necesario del núcleo predicativo.

"De los toros más vale no hablar porque yo para mí no hay cosa más salvaje que los toros. Que los romanos en aquel tiempo pusieron aquello, bien, pero que en la época actual el hombre disfrute viendo cómo otra persona..." C1H4096 
Que el hombre actual disfrute y vea cómo otra persona / disfrute mientras ve cómo otra persona

Que el hombre actual disfrute así, de este modo

¿Cómo disfruta el hombre actual?

Entendemos, por lo tanto, que es inadecuada la terminología frecuentemente utilizada en el estudio de las perífrasis de verbo auxiliar y auxiliado pues falsea la verdadera relación sintáctica de interdependencia existente en los complejos verbales perifrásticos. Entre las dos unidades constituyentes se establece una relación de reciprocidad, de necesidad o de incidencia mutua o bidireccional y no solamente en un sentido. A falta de una propuesta mejor, optamos por llamar a las dos unidades por sus rasgos morfológicos: forma flexiva y forma no flexiva o usar sinónimos como conjugada / no conjugada o flexionada / no flexionada.

Ahora bien, es preciso delimitar a qué nivel se establece la relación de interdependencia aludida. Para ello diferenciaremos dos partes en la exposición: sintaxis y semántica, o lo que es lo mismo, forma y contenido.

\subsubsection{Forma}

En el nivel formal, la relación de interdependencia se pone de manifiesto en la morfología de las dos unidades del complejo verbal perifrástico. Tal relación de solidaridad se advierte en tanto que el verbo conjugado aporta las desinencias de tiempo, modo, persona y número y el no conjugado representa el aspecto.

La noción de aspecto plantea problemas de identificación y caracterización, lo que ha supuesto que existan diferentes interpretaciones. No es nuestra intención resolver tan ardua cuestión sobre la que tanto se ha escrito pero sí consideramos necesario exponer de forma clara los criterios que manejaremos en nuestra exposición. Parece existir una opinión unánime entre los tratadistas por la cual está bien delimitada la frontera entre lo que ha sido llamado aspecto y lo que se ha llamado modo de acción. Lo primero es un término de carácter gramatical y lo segundo guarda relación con el contenido sémico del lexema verbal.

A partir de aquí se plantea el problema de la delimitación de los posibles matices aspectuales que es posible encontrar en el análisis de las perífrasis verbales, principalmente las de gerundio. Desde nuestro punto de vista se advierten dos tendencias diferentes:

En primer lugar hay lingüistas, G. Rojo (1974) y V. Lamíquiz (1982), entre otros, que entienden el aspecto en un sentido que podemos llamar "amplio". Desde esta perspectiva se defiende que la noción aspectual permite explicar no solamente procesos que guardan relación con el término (perfectivo) o no término (imperfectivo) de la idea verbal, sino que en él quedan representados procesos de repetición, progresión, incoación, etc. En palabras de G. Rojo (1974:21): "Hemos de considerar lo perfectivo, imperfectivo, incoativo, terminativo, etc. al mismo nivel dado que se refieren a la acción en sí misma". De este modo se entiende que las perífrasis verbales constituyen uno de los principales recursos que 
contiene el español para expresar los matices aspectuales antes citados, los cuales no se pueden conseguir con la flexión del verbo.

En segundo lugar mencionamos otra interpretación del aspecto verbal que podríamos llamar "restringida" que sitúa dicha noción gramatical entre los polos opuestos de término y no término del proceso verbal (aspecto perfectivo e imperfectivo). Destacamos como representante de esta segunda interpretación a E. Alarcos (1970). Este autor hace la distinción entre aspecto flexional, representado por las desinencias del verbo y aspecto sintagmático que se pone de manifiesto en las formas compuestas del paradigma verbal. Además, considera que entre las formas no conjugadas del verbo, infinitivo, gerundio y participio se establece una oposición aspectual tripartita que E. Alarcos (1970:60) explica del siguiente modo: "el miembro positivo es el "participio", por indicar el proceso con su término (su límite), miembro negativo el "gerundio", por indicar el proceso sin su término, miembro neutro el "infinitivo", por indicar el proceso sin atender a la posibilidad de término, esto es, en reposo."

Entendemos, junto con E. Alarcos (1970) que el aspecto es una particularidad gramatical mediante la cual se alude al proceso interno del verbo, esto es, al término o no de la idea verbal. De este modo distinguiremos solamente entre aspecto perfectivo, representado en el participio, imperfectivo, contenido en el gerundio y la ausencia de ambos, que se pone de manifiesto en el infinitivo. El gerundio en tanto que elemento no marcado que indica el no término de la acción se convierte en una forma adecuada para la expresión de un proceso durativo, en desarrollo. Tal aspecto imperfectivo, de acción en curso, es el que aporta el gerundio a los complejos verbales perifrásticos de los que forma parte.

Una vez delimitada la noción de aspecto que defendemos es preciso señalar que no creemos que sea posible admitir que las perífrasis verbales de gerundio sean recursos de carácter gramatical para la expresión de aspectos progresivo, incoativo, reiterativo, frecuentativo, etc. Tal afirmación nos llevaría a considerar de forma conjunta factores gramaticales y semánticos como definidores del aspecto verbal. A nuestro juicio, la progresión, la reiteración, la incoación, entre otros, son matices contextuales que superan el plano de lo gramatical y que están condicionados por la semántica de los verbos constituyentes de una perífrasis (tanto del conjugado, $v a$ aprendiendo, como del no conjugado, está evolucionando) y por las secuencias adverbiales situadas en el entorno de las aquéllas (está aprendiendo poco a poco). Hablaremos por tanto de matices contextuales y no de aspecto para referirnos a los valores antes señalados. De esta forma, en una perífrasis verbal de gerundio, el aspecto imperfectivo es una constante que se manifiesta en dicha forma no flexionada y tal valor aspectual se combina con matices semánticos variables que se actualizan en las situaciones comunicativas concretas. J. Roca Pons (1960:241) recoge con fidelidad la idea que aquí defendemos. En opinión del autor, junto con el "valor durativo fundamental" es posible advertir "otros matices" que pueden ser continuativo, de reiteración, entre otros.

Retomando la cuestión con la que abríamos este apartado, entendemos que entre el

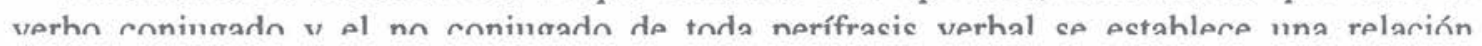


gramatical de interdependencia. Al igual que una forma verbal simple está constituida por sus desinencias, la perífrasis es una unidad de carácter analítico en la que los morfemas de tiempo, modo, persona y número se manifiestan en verbo flexionado y el aspecto se pone de manifiesto en la unidad no conjugada. No creemos, por lo tanto, que toda la perífrasis constituya una representación analítica de la noción aspectual sino que el gerundio es el que aporta el aspecto imperfectivo a todo el complejo verbal.

\subsubsection{Contenido}

Si bien en el nivel formal, como acabamos de ver, se advierte una relación de interdependencia entre las dos partes del complejo verbal perifrástico, creemos que tal relación puede también defenderse en el plano semántico. Para ello es preciso analizar qué es lo que aporta cada una de las partes integrantes al conjunto.

El proceso semántico que se opera sobre el verbo flexionado de una perífrasis verbal no debe explicarse como una pérdida del significado pleno del verbo sino que puede interpretarse como la actualización de un sentido en un contexto discursivo concreto. Según M. Launay (1980:43) hablar de significado propio exige entender que existe un valor semántico primario y otros secundarios. De este modo, es preferible considerar la existencia de una carga sémica virtual, un significado lingüístico que poseen todos los lexemas y que, en las distintas situaciones discursivas actualizan unos semas u otros. En el caso de los complejos perifrásticos, el verbo conjugado no actualiza los semas que le aportan un contenido designativo sino que se pone de manifiesto un sentido intrínseco al verbo y dirigido hacia las coordenadas del texto. En opinión de M. Morera (1991) el verbo ir, por ejemplo, adopta un sentido de 'alejamiento físico' en el sintagma iré a la playa, mientras que en el complejo verbal las cosas van mejorando se pone de manifiesto un sentido figurado de 'movimiento hacia una situación diferente', en este caso favorable. El verbo ir significa 'movimiento' pero no físico sino intraverbal, movimiento de una situación a otra diferente. En este caso necesita del gerundio para actualizar dicha significación.

Además, el gerundio aporta al conjunto de la perífrasis su base conceptual o léxica. Se pone de manifiesto una relación de interdependencia en tanto que si por un lado la perífrasis necesita del matiz semántico que ofrece el verbo conjugado para constituir una secuencia de sentido diferente a las unidades integrantes, que es la construcción perifrástica, por otro lado, la presencia en el discurso del gerundio favorece la actualización de un sentido de la forma conjugada distinto al que se manifestaría si tuviera otra palabra como modificador (cualquier otra secuencia sintagmática), como se vio en el ejemplo propuesto previamente con el verbo $i r$. Igualmente, como ya señalamos en el apartado anterior, la carga sémica del lexema verbal en gerundio contribuye a la interpretación contextual de valores de progresión, reiteración, etc. que repercuten en el conjunto del grupo perifrástico y que pueden estar favorecidos por la semántica del verbo conjugado y por las secuencias adverbiales del entorno sintáctico inmediato.

"Pero lo que pasa es que cada vez la vida que vivimos es más apresurada y este sentido tan negativo de esta prisa que todos estamos desarrollando cada día, pues, no sé, nos quita 
tiempo para nuestras más profundas y auténticas aficiones, como ésta de la lectura." C2H4195

El significado del verbo desarrollar y la secuencia adverbial cada día añaden al complejo verbal perifrástico un sentido de proceso gradual reiterativo

Concluimos que, en el plano semántico, las dos unidades de un complejo verbal perifrástico mantienen una relación de interdependencia o solidaridad. La forma verbal flexiva aporta al conjunto la carga sémica que actualiza en el discurso, sentido no designativo sino coordenativo, mientras que la forma verbal no flexiva constituye la base léxica de todo el conjunto, modificada por la unidad anterior. De la unión de ambas partes resulta una significación conjunta y distinta a la realización como unidades independientes.

\section{3. ¿Unidad de la lengua o unidad del discurso?}

Una última cuestión que es preciso plantear en la caracterización de las perífrasis verbales es si son unidades que pertenecen a la virtualidad del sistema o si, por el contrario, son manifestaciones discursivas que resultan de las necesidades expresivas de un contexto de comunicación. No faltan quienes opinan que la secuencia perifrástica estar + gerundio está en oposición paradigmática con la forma compuesta del verbo haber + participio. La primera indica el proceso en su transcurso de realización y la segunda señala el final de la acción. F. Marcos Marín (1972:186 y ss.) incluye ambas formas en lo que el autor llama modificadores secundarios que, en el paradigma, constituyen una forma sintagmática de representación aspectual que se completa con los modificadores primarios (sufijación verbal) y los modificadores terciarios (las perífrasis verbales). Estos últimos, señala el autor, contienen matices de significación para-aspectuales que, además, son un recurso de variación estilística.

Si bien hay lenguas como el inglés que soportan un análisis que incluye a las secuencias estar + gerundio dentro del paradigma verbal, seguimos a E. Alarcos (1970:84) en su opinión de que tal explicación no puede aplicarse al sistema verbal del castellano. Este autor entiende que, dado que la forma conjugada de la construcción perifrástica posee sus propios morfemas de flexión, el conjunto de la secuencia no puede entenderse como una estructura sintagmática del paradigma para la expresión del aspecto.

Los complejos verbales perifrásticos son el resultado de la unión en el discurso de dos unidades virtuales del sistema para agruparse en una secuencia sintáctica y semánticamente distinta. No son, por lo tanto, unidades del paradigma, pues un mismo complejo verbal puede ser o no perifrástico, dependiendo de las condiciones comunicativas y contextuales del discurso. Creemos que una misma forma verbal, como virtualidad potencial del sistema, puede tener o no un comportamiento perifrástico en determinados contextos. Dicho comportamiento, pensamos, no depende sólo de su manifestación formal (unidad flexiva del verbo + unidad no flexiva) sino que han de darse unas condiciones sintácticas (funcionamiento como una sola unidad predicativa, la forma conjugada pierde su régimen propio, entre otros), semánticas (el verbo conjugado adquiere un sentido interno y el verbo no conjugado aporta una base léxica al conjunto) y discursivas (existencia o no de 
complementos entre las dos formas verbales e intencionalidad comunicativa del hablante, entre otros) favorables para la formación de un complejo verbal perifrástico.

Las perífrasis verbales son hechos de habla (Cf. J. Alcina y J. M. Blecua, 1975:780), producto de un proceso pragmático de enunciación. Ésta fue entendida por E. Benveniste (1966:81) como "la conversion individuelle de la langue en discours." Una perífrasis verbal constituye la actualización en el discurso de una secuencia unifuncional y de un recurso expresivo que supera las posibilidades virtuales del sistema. En este proceso están implicadas las nociones de sincronía y diacronía. Los complejos verbales que aquí analizamos no forman parte del sistema verbal del castellano actual porque no constituyen secuencias fijas entre las que se establece una oposición paradigmática. Esto no impide que el paso del tiempo permita su establecimiento como secuencias sistemáticas cuya interpretación perifrástica no dependa de la situación discursiva. No obstante, es preciso señalar que en un estudio sincrónico como el que nos ocupa no puede más que afirmarse su condición de hechos de habla que no han alcanzado una situación estable y definitiva. Por lo tanto, la consideración de un complejo verbal como perifrástico es un proceso que, en el estado actual de la lengua, necesita de un contexto comunicativo adecuado. Esto justifica los casos de confusión donde es complicado delimitar su funcionamiento o no como un solo núcleo verbal. Creemos que, en última instancia, la consideración o no de un complejo verbal como perifrástico queda reducido a la intencionalidad del hablante a la cual el lingüista no puede acercarse con total precisión.

\section{ANÁLISIS DEL CORPUS}

Nos ocupamos ahora de la descripción y análisis discursivo de las perífrasis verbales de gerundio utilizadas por los hablantes sevillanos cultos. ${ }^{5}$ Existen varias posibilidades de agrupación y clasificación de las perífrasis verbales. Quizás la más utilizada es aquélla que, siguiendo criterios externos y formales, distingue tres grupos según la forma no flexiva del verbo: perífrasis verbales de infinitivo, gerundio y participio. En este trabajo partimos ya de antemano de dicha primera clasificación externa, puesto que hemos centrado nuestro estudio en el análisis de las formas perifrásticas de gerundio. A partir de ahí, en este trabajo adoptamos un planteamiento semasiológico por el cual partimos de la forma del verbo conjugado (estar, ir, etc.) para, posteriormente, analizar los sentidos contextuales que los complejos verbales perifrásticos adquieren en el discurso. El carácter de hecho discursivo que identifica a las perífrasis verbales justifica algunas zonas de confusión acerca del comportamiento perifrástico de los núcleos verbales considerados.

El gerundio es una de las formas verbales que ha despertado gran interés por las múltiples y variadas funciones que cumple en el discurso ${ }^{6}$. Entre ellas, cabe destacar que en

\footnotetext{
${ }^{5}$ En el análisis de la lengua hablada nos unimos a la labor conjunta del "Estudio de la norma lingüística culta de las principales ciudades de Hispanoamérica y España”, Proyecto en el que participan otras ciudades. Señalamos los trabajos de E. Luna (1980) y H. I. Otálora (1992) como referentes inmediatos de corpus similares al nuestro en los que fueron analizadas las perífrasis verbales de gerundio.
}

${ }^{6}$ Es posible hacer una distinción en dos grandes grupos (Cf. E. Luna, 1980; H. I. Otálora, 1992): 
el habla urbana culta de Sevilla la más rentable fue aquélla en la que dicha forma no flexiva forma parte de una construcción perifrástica (Cf. F. Rodríguez-Izquierdo, 1981). El orden que seguiremos para el análisis de las perífrasis verbales de gerundio será el de mayor a menor frecuencia de casos registrados y, en caso de coincidencia, el orden alfabético. A modo de síntesis, exponemos a continuación el tipo de unidades encontradas en el corpus, así como su frecuencia de uso:

\begin{tabular}{ccc}
\hline PERIFRASIS DE GeRUNDIO & FReCUENCIA ABSOLUtA & FReCUENCIA RELATIVA / 183 \\
\hline Estar + gerundio & 108 & $59.01 \%$ \\
Ir + gerundio & 46 & $25.1 \%$ \\
Seguir + gerundio & 20 & $10.9 \%$ \\
Continuar + gerundio & 5 & $2.7 \%$ \\
Andar + gerundio & 2 & $1.09 \%$ \\
Salir + gerundio & 2 & $1.09 \%$ \\
\hline Total & 183 & $100 \%$ \\
\hline
\end{tabular}

Perífrasis verbales de gerundio en el habla urbana culta de Sevilla

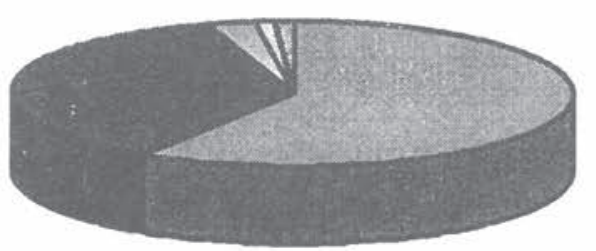

\begin{tabular}{|l|}
\hline Estar + gerundio \\
Ir + gerundio \\
Seguir + gerundio \\
$\square$ Continuar + gerundio \\
$\square$ Andar + gerundio \\
$\square$ Seguir + gerundio
\end{tabular}

- El gerundio puede funcionar como el núcleo de oraciones independientes, coordinadas y subordinadas, estas últimas adjetivas o adverbiales. Además, dicha unidad lingüística puede adquirir las funciones de adyacente de sustantivo (adjetivales) o de verbo (adverbiales) sin constituirse como el núcleo de una oración, esto es, sin modificadores verbales propios.

- El gerundio puede ser parte del núcleo verbal del predicado formando, en una relación de interdependencia con una forma conjugada del verbo, un complejo verbal perifrástico. 


\subsection{Estar + gerundio $(108 / 183,59.01 \%)$}

Las perífrasis de estar + gerundio son las que han sido registradas en nuestros materiales con una mayor frecuencia (108 casos, $59.01 \%$ del total de las perífrasis de gerundio, 183$)^{7}$. Esta elevada frecuencia en los hablantes cultos sevillanos viene a coincidir con el resultado de otros trabajos realizados en diferentes núcleos urbanos (Cf. E. Luna, 1980; H. I. Otálora, 1992). En opinión de M. Morera (1991:215) el verbo estar sigue manteniendo su contenido invariante de permanencia en una situación. Lo que sucede es que ahora no apunta hacia una realidad designativa externa sino hacia una significación intradiscursiva, en relación con la acción verbal. El conjunto de la perífrasis verbal estar + gerundio aporta al discurso un contenido de acción en proceso, en desarrollo, sin añadir nuevos matices semánticos. Tal es así que, como vimos, autores como F. Marcos Marín (1972:186) consideran la existencia de un modificador secundario, a un nivel diferente de las perífrasis verbales, las cuales expresan, además, factores estilísticos.

Coincidimos con la opinión de S. Fernández Ramírez (1960:512) para quien los complejos verbales perifrásticos estar + gerundio introducen efectos estilísticos distintos a los que aporta la forma simple del verbo. Con la perífrasis se consigue una mayor insistencia en el desarrollo de la idea verbal, en su proceso.

En lo que respecta a las características morfológicas, aparece en el corpus un predominio de las formas conjugadas en indicativo (103/108, lo que supone un $95.4 \%)$, frente a sólo 2 casos en presente de subjuntivo (1.9\%), uno de ellos exigido por el verbo principal y el otro por la modalidad de la oración. Las 3 unidades restantes $(2.8 \%)$ forman parte de una perífrasis verbal de infinitivo con valor de obligación.

"Bueno, quizás sea una cosa general, de todas las ciudades, pero quizás aquí esté entrando más ahora." C2H1161

"O sea, se creen que siempre tienen que estar cantando por las calles o armando alboroto" $\mathrm{C} 3 \mathrm{H} 3280$

La distribución por tiempos refleja una preferencia de las formas verbales del presente de indicativo $(79 / 108,73.1 \%)$, seguido del imperfecto $(14 / 108,12.9 \%)$, del pretérito perfecto simple $(3 / 108,2.8 \%)$, del pretérito perfecto compuesto $(6 / 108,5.6 \%)$ y 1 solo caso registrado de condicional compuesto $(0.8 \%)$.

\footnotetext{
${ }^{7}$ Solamente consideramos complejos verbales perifrásticos aquellas secuencias de estar + gerundio entre las que no medie ningún elemento de carácter adverbial que convierta al verbo estar en un núcleo con capacidad predicativa con el contenido designativo de 'permanencia en un lugar'. Así no caracterizamos como un grupo verbal conjunto ejemplos del tipo "Y estuve alli estudiando hasta sexto de bachiller." (C1H2067) porque ambos verbos tienen independencia predicativa que les permite convertirse en un grupo disjunto (estuve allí y estudie). La relación sintáctica entre ambos es de subordinación del gerundio con respecto al verbo estar. Solamente admitimos como secuencias perifrásticas aquellos casos mediatos de estar + gerundio en los que el elemento interpolado es el sujeto (no encontramos ningún ejemplo con estar + gerundio): "Cuando uno nace en un barrio se va uno aclimatando a sus costumbres" (C2V1109) o alguna otra partícula que no destruya la unidad sintáctica y semántica del grupo: "Está también haciendo la tesis doctoral" (C1H3082). En alguna ocasión, dos complejos verbales perifrásticos comparten una misma forma flexionada para evitar la redundancia: "Ésta está bajando y Sábado Gráfico subiendo de nivel" (C2H1155).
} 
El predominio del presente de indicativo no es de extrañar, sobre todo si tenemos en cuenta que es una forma con gran rentabilidad discursiva que puede utilizarse para la expresión de nociones de pasado, presente y futuro. Es posible señalar aquellos casos en que la idea verbal se refiere a un hecho puntual simultáneo al momento de la enunciación. El número de ocurrencias registradas en el corpus fue de $8 / 108,7.4 \%$. Como puede observarse, la frecuencia es bastante baja. Los resultados del análisis de nuestro material resultan contradictorios con la opinión de que la secuencia perifrástica estar + gerundio sirve para señalar hechos relacionados con el mismo momento de la enunciación. Tal es el caso de L. Gómez Torrego (1988:141) para quien "las perífrasis de gerundio con estar se usan, sobre todo, para referirse a procesos de duración más corta y concreta."

"Como ya estoy hablando despacio, ya digo el centro, yo digo «el sentro»." C3H1249

Cuando la perífrasis de estar + gerundio sirve para expresar un presente puntual, los verbos que se utilizan representan acciones que se refieren al momento de la enunciación. En nuestro material, 7 de los 8 casos registrados fueron verbos de lengua (hablar y la expresión cogerse los dedos con el sentido de 'equivocarse') y en el ejemplo restante se utiliza el verbo grabar, acción que se está realizando en el momento de la conversación.

"Pero claro, estamos hablando de cosas muy difíciles" $\mathrm{C} 2 \mathrm{H} 3182$

"Lo que no sé si me estoy cogiendo los dedos, como suele decirse, al hablar aŝ́" C2H3182

“YYa estás grabando?” C2V2119

$\mathrm{Al}$ igual que señaló H. I. Otálora (1992), observamos que en nuestro material ni siquiera aquellos casos en que aparece una partícula adverbial que situarían el hecho enunciado en el mismo momento del habla (ahora, ahora mismo) representan una idea verbal simultánea a la enunciación. Tales partículas tienen, pues, un sentido más extenso en el tiempo.

"Sí. Pues tiene... Bueno, ahora mismo todavía se está construyendo de Barcelona a Zaragoza, porque ahora es terrible ir." C1V1007

Es más frecuente el uso de la perífrasis estar + gerundio en el presente de indicativo cuando expresa un hecho que no coincide exactamente con el momento del habla, sino que contiene una idea que viene del tiempo anterior a la enunciación y que continúa en el presente extenso que supera la situación conversacional. Tal es el caso de los ejemplos señalados previamente y el que indicamos a continuación en los que la partícula adverbial no limitaba la idea verbal al momento del acto comunicativo.

"Yo me estudié la materia y me sabía los autores, la biografía y sus obras, pero no sabía, como este año nos está enseñando ella, a comentar textos, a saber leer una novela, a hacer fichas." C1H1059

No faltan los casos en los que la perífrasis de estar + gerundio expresa una idea de presente habitual. Especialmente claros son aquellos enunciados en los que la idea de acción repetida aparece reforzada por la presencia en el discurso de una secuencia de carácter adverbial. 
"Porque, claro, si va solamente una familia, que se están viendo todos los días, a dar un paseíto por la Feria, eso no es ambiente." C3H4294

Las encuestas del habla urbana culta de Sevilla reflejan la poca frecuencia de la negación en las construcciones perifrásticas de estar + gerundio, como señalaba $\mathrm{S}$. Fernández Ramírez (1960), no habiendo aparecido ningún caso.

Nos ocupamos ahora de los matices contextuales que adquieren los complejos perifrásticos de estar + gerundio en el material analizado. El valor discursivo más generalizado que ponen de manifiesto es el de la expresión neutral de la duración de la idea verbal.

"Bueno después de esta breve interrupción se me ha ido un poco la idea de lo que estábamos hablando." $\mathrm{C} 2 \mathrm{H} 4192$

Se han registrado otros casos, no obstante, en que se actualiza en el discurso la idea de progresión o evolución. Tal posibilidad expresiva se debe a factores contextuales. Tanto el valor semántico del gerundio como los modificadores adverbiales del entorno inmediato (de este último caso no registramos ningún ejemplo en el material), pueden favorecer el sentido de progresión.

"Ahora, pues, parece ser que esto está transformándose mucho con las reuniones de padres, de tal y de cual, [...]." C2H2172

Se observaron también ocurrencias en las que la idea que aporta al discurso la estructura perifrástica es la de un proceso que se prolonga de forma reiterativa. Las secuencias adverbiales que expresan una idea de repetición son los principales agentes de ese sentido discursivo.

"No, y, además, hay niños que la clase se le hace cortísima, están disfrutando, están observando continuamente lo que tienen delante, [...]" C2V2119

En otras ocasiones se advierte que la perífrasis estar + gerundio contiene un valor incoativo. En ellas se expresa una idea de comienzo, aunque manteniéndose siempre el carácter de duración que aporta la forma no flexiva.

"Porque ya decía antes que hay algunas cofradías que se han puesto al compás de los tiempos, al compás del Concilio Vaticano II, y han hecho grandes reformas de sus reglas, se están adaptando a las consignas de la Iglesia." C3V2218

'comienzan a adaptarse'

Es quizás el carácter eminentemente narrativo del corpus manejado, así como la pérdida de cierto grado de espontaneidad que implica la situación de entrevista lo que haya favorecido la ausencia de usos de estar + gerundio en secuencias exclamativas con valor imperativo ( Ya te estás callando!) ${ }^{8}$. Se trata, como señala E. Lorenzo $(1966: 126)$ de

\footnotetext{
${ }^{8}$ Ejemplo utilizado por E. Lorenzo (1966:126).
} 
fórmulas de gran expresividad que, nos consta, son conocidas entre los hablantes sevillanos. En ellas, dice L. Gómez Torrego (1988:145) se adelanta el proceso de la acción que aún no se ha realizado.

\section{2. $I r+$ gerundio $(46 / 183,25.1 \%)$}

Es la segunda construcción perifrástica en número de frecuencias registrada en el material con un total de 46 unidades absolutas ${ }^{9}$, lo que supone un $25.1 \%$ del conjunto de los complejos verbales perifrásticos de gerundio. Si bien estar + gerundio representaba por excelencia la duración de la acción, en las perífrasis de ir + gerundio la característica principal es el matiz de progresión que aporta el verbo de movimiento al conjunto. Se indica, además del proceso en desarrollo, la existencia de un progreso continuo y gradual que, en ocasiones, aparece reforzado por la semántica del verbo en gerundio o por la presencia en el discurso de secuencias adverbiales.

"Pero también la vida evoluciona, la moda tiene que ir evolucionando, los gustos van evolucionando, los colores evolucionan, todo en realidad." $\mathrm{C} 1 \mathrm{H} 4096$

"Y tantas cosas como hay ocultas por ahí que ya se irán poco a poco descubriendo." C3V2221

En los complejos perifrásticos, el verbo ir no expresa un contenido designativo, un movimiento físico que indica desplazamiento en el espacio sino que expresa un sentido intraverbal de desarrollo gradual de un proceso, de la idea verbal (Cf. M. Morera, 1991:221).

La realidad morfológica que estos complejos verbales perifrásticos han reflejado en nuestro corpus es similar a la que la que observábamos en las formas de estar + gerundio. Sigue existiendo un predominio del modo indicativo (35/46, $76.1 \%$ ), frente al uso del presente de subjuntivo $(2 / 46,4.3 \%)$ y de la forma no flexiva de infinitivo $(9 / 46,19.6 \%)$. Estas últimas incluyen formas oracionales con función de sustantivo, secuencias perifrásticas con valor de obligación (tener + infinitivo) y estructuras con valor causal precedidas de la preposición por.

"Pero también la vida evoluciona, la moda tiene que ir evolucionando, los gustos van evolucionando, los colores evolucionan, todo en realidad." C1H4096

"Quizás, a la larga, las generaciones se vayan acostumbrando al estudio, [...]" C3H3285

"Ya cuando el coche ha llegado a cierta vejez, por ir aumentando un poco socialmente, $\{\ldots .$. C1V1009

Las variantes temporales reflejan de nuevo un predominio de las formas del modo indicativo, con un mayor uso del presente $(21 / 46,45.7 \%)$; seguido del imperfecto (8/46,

\footnotetext{
${ }^{9}$ Consideramos que el siguiente complejo verbal no tiene un comportamiento perifrástico porque la inclusión de la secuencia sintagmática con valor adverbial entre el verbo conjugado y el no conjugado hace que el primero adquiera en el discurso un contenido designativo y que toda la secuencia forme un grupo disjunto (van y guardan)::“O sea, que van por la calle guardando todos el sitio, todos callados, todas esas cosas." C3H4292
} 
$17.4 \%)$, del pretérito perfecto simple $(3 / 46,6.5 \%)$, del pretérito perfecto compuesto $(2 / 46$, $4.3 \%)$ y de 1 caso de futuro $(2.2 \%)$.

De nuevo el predominio de las formas de presente se debe a su multifuncionalidad en el discurso y a las características propicias del corpus, de carácter conversacional. Destacamos los valores actual y habitual, frente a la ausencia de sentidos puntuales que son contrarios a la idea de progreso que caracteriza a estas construcciones perifrásticas.

"Y, en realidad, pues al paso que va evolucionando la vida, tampoco se puede pretender que una persona se estacione haciendo zapatos toda la vida." C3H3285

"Es de estas personas que, cuando hay que decir algo, lo dice sin dar vueltas, o sea, que lo dicen en la cara y no van diciendo por detrás ni nada de eso." C1H1054 'habitualmente'

El valor que, de forma predominante, expresan en el discurso las secuencias perifrásticas de $i r+$ gerundio es el de proceso durativo en progresión gradual, como hemos visto en los ejemplos aportados hasta el momento. Es posible, sin embargo, advertir un carácter marcadamente reiterativo en algunas construcciones de este tipo, principalmente en aquéllas que estén apoyadas por una secuencia adverbial que aporte tal condición repetitiva.

"Llegó quinto y escogí la rama de letras y cada vez me iba sintiendo más inclinada." C1H2068

Igualmente señalamos un caso en el que el contexto sintagmático inmediato a la perífrasis favorece la interpretación de un matiz incoativo que se suma al de duración y progresión que identifica a estas secuencias.

"Hasta tal punto de que ello lo va comprendiendo últimamente la Iglesia." C3V4244

'lo empieza a comprender'

No se ha registrado ninguna ocurrencia en nuestro material en la que la secuencia perifrástica $i r+$ gerundio se utilice en un enunciado exclamativo para la expresión de una orden (Id haciendo la comida). Es preciso señalar que creemos que la ausencia de tales usos se debe a las características del material analizado y no a que sean construcciones desconocidas por los hablantes sevillanos.

\subsection{Seguir + gerundio $(20 / 183,10.9 \%)$}

En nuestro material seguir + gerundio no es una secuencia perifrástica tan productiva como las anteriores. Se registraron 20 ocurrencias, lo que supone una frecuencia relativa de 10.9. \% sobre el resto de las perífrasis analizadas. Este complejo perifrástico indica la continuidad de un proceso de carácter durativo que procede del pasado y se mantiene en el presente. El verbo seguir, como apunta M. Morera (1991:238) contiene un significado invariante que se entiende como 'movimiento en la línea de' que, en la situación discursiva de un complejo verbal perifrástico, no representa un contenido designativo de desplazamiento físico o espacial, sino que adquiere un sentido coordenativo de continuación de una idea verbal. 
La morfología de estos complejos perifrásticos refleja de nuevo una preferencia por los tiempos de indicativo $(15 / 19,78.9 \%) \mathrm{y}$, dentro de éstos, todas las formas verbales fueron utilizadas en presente. Se manifiesta el valor del presente actual, en detrimento del puntual, pues el contenido de proceso continuo en el momento presente que se expresa en esta perífrasis necesita de una extensión del proceso que, por lo general, supera la simultaneidad al acto de habla.

"A mí me sigue gustando algunos de sus aspectos, muy escondidos, muy ocultos dentro de las iglesias, en algunos de los barrios y demás.” $\mathrm{C} 3 \mathrm{H} 2265$

El valor de prolongación de un proceso durativo que viene del pasado y que se mantiene de forma continuada el presente identifica a todas las secuencias perifrásticas de seguir + gerundio registradas en las encuestas, sin adquirir matices contextuales diferentes.

\subsection{Continuar + gerundio $(5 / 183,2.7 \%)$}

Se registraron 5 casos (2.7\% sobre el total de perífrasis analizadas) de complejos verbales perifrásticos con la forma continuar + gerundio.

\section{“Al sevillano continúa gustándole, al sevillano le continúa gustando ir a ver los pasos, como} se suele decir, a ver las cofradías." C1V2020

Entre los tratados consultados hemos encontrado la opinión de aquéllos que piensan que es solamente una variante estilística y sinónima de seguir + gerundio (Cf. L. Gómez Torrego, 1988), frente a los que creen que ambas expresiones no son semánticamente idénticas y que hay matices diferenciales entre una y otra (Cf. M. Morera, 1991:241). Considera este último autor que en ambos casos se manifiesta el interés por el desarrollo sin interrupción del proceso pero que: "mientras que con continuar se significa la 'duración' como 'prolongación de algo anterior', sin más, con seguir se significa como 'movimiento en la línea de'. Es decir, en el primer caso, se subraya la primera fase; en el segundo, se pone el énfasis en la segunda."

El escaso número de ocurrencias registradas en las encuestas no nos permite establecer conclusiones decisivas. Intuimos, no obstante, que se trata de un proceso de variación sinonímica por el cual dos expresiones perifrásticas contienen un mismo valor discursivo (prolongación de un proceso verbal de carácter durativo que procede del pasado y que se manifiesta de forma continuada en el presente). La conmutación de una forma por otra no supone una alteración de su identidad semántica ni sintáctica. En nuestro corpus aparece un mismo informante que utiliza, en nuestra opinión indistintamente, las dos variantes. Creemos que lo que diferencia a las dos construcciones perifrásticas es la rentabilidad comunicativa, siendo seguir + gerundio más utilizada. Esto es lo que hace que ciertas construcciones de continuar + gerundio resulten extrañas, pues su uso es más escaso.

\subsection{Andar + gerundio $(2 / 183,1.09 \%)$}

Esta secuencia perifrástica resultó poco rentable entre los hablantes sevillanos. Solamente se registraron 2 casos $(1.09 \%$ del total de perífrasis de gerundio) que tienen 
como particularidad el estar en una construcción coordinada y compartir un mismo verbo conjugado.

“[...] y sabe encontrar en ello algo después de andar buceando y aislándose del exterior de una manera enorme." C3H2266

En estas construcciones la forma verbal flexiva no expresa un desplazamiento físico sino que expresa la prolongación de un proceso durativo, al que se le añade el matiz de reiteración. No se establecen límites temporales ni espaciales fijos (a diferencia de $i r$ que es un movimiento desde el presente hacia el futuro, y venir que es un movimiento desde el pasado hasta el presente). Esta idea de movimiento indeterminado favorece que las construcciones de andar + gerundio adquieran en el discurso sentidos de indecisión, inestabilidad o, como señala L. Gómez Torrego (1988:150) "efectos de desazón, ironía, ansiedad, etc. [...] Algo nos anda rondando por la cabeza". La falta de unidades en nuestro material nos impide observar esta diferencia de matices.

\subsection{Salir + gerundio $(2 / 183,1.09 \%)$}

Registramos 2 casos de complejos verbales salir + gerundio con valor perifrástico en las encuestas, lo que supone una frecuencia relativa de $1.09 \%$ sobre el total de perífrasis de gerundio.

El verbo conjugado salir que M. Morera (1991:233) entiende como 'movimiento de dentro hacia fuera con superación de límites' no tiene un sentido designativo de desplazamiento físico sino que, como sucede en las construcciones perifrásticas, aporta un contenido intraverbal relacionado con una acción en proceso. De este modo, la perífrasis salir + gerundio añade al aspecto imperfectivo, acción en desarrollo, en unos casos, un contenido contextual incoativo por el que se expresa 'cambio de situación de forma espontánea o inmediata' (no hemos registrado ningún ejemplo en los materiales analizados: cuando menos nos lo esperábamos salió diciendo que no tenía dinero) y, en otros casos se expresa 'resultado', como se advierte en:

"[...] por la peseta te dan muchos más bonos que eslotis, o sea, que tú sales ganando al cambio." $\mathrm{C} 1 \mathrm{H} 3087$

'Terminan por ganar'

$\mathrm{Al}$ igual que veíamos en el apartado anterior, la rentabilidad de esta construcción en el habla de los sevillanos cultos fue muy baja, por lo que necesita de contextos comunicativos muy delimitados.

\section{CONCLUSIONES}

De la caracterización y posterior análisis de las perífrasis verbales de gerundio en el habla urbana culta de Sevilla podemos concluir que dichas unidades lingüísticas son secuencias discursivas producto de un comportamiento pragmático en las situaciones comunicativas, por lo que su delimitación resulta difícil fuera de cualquier contexto. Son 
construcciones formadas por un verbo conjugado y otro no conjugado entre los que se establece una relación de interdependencia sintáctica y semántica.

Las perífrasis que resultaron más productivas en el habla urbana culta de Sevilla fueron aquéllas formadas por estar + gerundio en las que, de forma predominante, se aporta una idea de proceso en desarrollo. También hubo una representación importante de aquéllas que expresan principalmente la prolongación de un proceso en desarrollo formadas por ir + gerundio. El resto de las perífrasis encontradas (seguir, continuar, andar, salir + gerundio) registró unos índices de frecuencias bastante escasos, como también se puso de manifiesto en estudios similares de análisis de la lengua hablada de otras ciudades. Las dos primeras construcciones perifrásticas señaladas son, en este sentido, secuencias más consolidadas que adquieren valores diversos en el discurso. Puede decirse, por último que, aunque los complejos verbales perifrásticos permitan la conmutación por las formas simples del verbo, desde una óptica de la información y de la intencionalidad comunicativa del hablante no son unidades equivalentes. Las perífrasis verbales de gerundio son recursos no sistemáticos, esto es, no pertenecen al paradigma verbal del español, que contribuyen a resolver las necesidades comunicativas de los hablantes y a aportar riqueza expresiva al idioma.

\section{BIBLIOGRAFÍA}

AlARCOS, E. (1970): "Sobre la estructura del verbo español", en Estudios de gramática funcional del español, $3^{\text {a }}$ ed., Madrid, Gredos, 1991, 50-89.

(1994): Gramática de la lengua española, Real Academia Española, Madrid, Espasa-Calpe.

AlcinA, J. y BleCUA, J. M. (1975): Gramática española, $8^{\text {a }}$ ed., Barcelona, Ariel:

ARJONA, M. (1992): "Las perífrasis estar + gerundio en el habla popular de la ciudad de México", en Scripta Philologica in honorem J. M. Lope Blanch, 303-311.

BenVEniste, E. (1966): “L'appareil formel de l'énonciation” en Problèmes de linguistique générale; II, Gallimard, 1974, 79-88.

BoBes, C. (1975): "Sistema, norma y uso del gerundio castellano", en Revista Española de Lingüística, 5, 1, 1-34.

CARbonero, P. (1993): "Ámbitos de modificación sintáctica adverbial" en Estudios lingüísticos y filológicos en honor de José Mondéjar en su sexagesimoquinto aniversario, Granada, Servicio de Publicaciones de la Universidad de Granada, 14-24.

Cuestionario para el estudio coordinado de la norma lingüística culta, Morfosintaxis, II, 1, P.I.L.E.I., C.S.I.C.

Fente, R., Fernández, J. y Feujoo, G. (1972): Perífrasis verbales, Madrid, Sociedad General Española de Librería.

FERNÁNDEZ DE CASTRO, F. (1990): Las perífrasis verbales en español: comportamiento sintáctico e historia de su caracterización, Universidad de Oviedo, Departamento de Filología Española. 
FERNÁNDEZ RAMíREZ, S. (1960): "Algo sobre la fórmula estar + gerundio", en Studia Philologica (Homenaje a Dámaso Alonso), II, 509-516.

Fontanella, Ma B. (1970): "Los auxiliares españoles", en Anales del Instituto de Lingüística, Universidad Nacional de Cuyo, X, 61-73.

GILI GAYA, S. (1943): Curso superior de sintaxis de la lengua española, 15ª ed., Barcelona, Bibliograf, 1993.

GÓMEZ TORREGO, L. (1988): Perífrasis verbales: sintaxis, semántica y estilística, Arco Libros.

HJelmSleV, L. (1943): Prolegómenos a una teoría del lenguaje, Madrid, Gredos, 1974.

HERNÁNDEZ, C. (1984): Gramática funcional del español, 3ª ed., Madrid, Gredos, 1996.

LAMíQuIZ, V. (1982): El sistema verbal del español, Málaga, Ágora.

LAMíquiz, V. (dr.) y CARBonero, P. (ed.) (1981): Sociolingüística Andaluza, 1: Metodología y estudios, Sevilla, Publicaciones de la Universidad de Sevilla.

LAmíquiz, V. (dr.) y PINEDA, M. A. (ed.) (1983): Sociolingüística Andaluza, 2: Encuestas del habla urbana de Sevilla. Nivel culto, Sevilla, Publicaciones de la Universidad de Sevilla.

LAUNAY, M. (1980): "Acerca de los auxiliares y frases verbales", en Lingüística Española Actual, II, 1, 39-79.

LENZ, R. (1925): La oración y sus partes, 3ª ed., Madrid, Centro de Estudios Históricos.

LORENZO, E. (1966): El español de hoy, lengua en ebullición, Madrid, Gredos.

LuNA, E. (1980): Sintaxis de los verboides en el habla culta de la ciudad de México, México, UNAM.

MARCOS MARÍN, F. (1972): Aproximación a la gramática española, Madrid, Cincel.

MORERA, M. (1991): Diccionario crítico de las perífrasis verbales del español, Puerto del Rosario, Cabildo Insular de Fuerteventura, Servicio de Publicaciones.

OTÁLORA, H. I. (1992): Uso del gerundio en algunas muestras del habla bogotana, Santafé de Bogotá, Publicaciones del Instituto Caro y Cuervo, Series Minor, XXXIV.

POTTIER, B. (1968): "Sobre el concepto de verbo auxiliar", en Lingüística moderna y filología hispánica, Madrid, Gredos, 194-202.

REAL ACADEMIA ESPAÑOlA (1973): Esbozo de una nueva gramática de la lengua española, Madrid, Espasa-Calpe, 1991.

RoCA PONS, J. (1958): Estudios sobre perífrasis verbales del español, Madrid, Consejo Superior de Investigaciones. (1960): Introducción a la gramática, Barcelona, Teide, 1976.

RODRÍGUEZ-IZQUIERDO, F. (1981): "Los morfemas de gerundio y de diminutivo en el habla de Sevilla", en Cauce, 4, 23-30.

RoJo, G. (1974): Perífrasis verbales en el gallego actual, Santiago de Compostela, Verba, Anexo 2.

SECO, R. (1931): Manual de gramática española, $9^{\mathrm{a}}$ ed., Madrid, Aguilar S.A., 1971. 